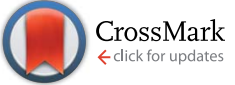

Cite this: RSC Adv., 2017, 7, 15428

Received 5th November 2016 Accepted 28th February 2017

DOI: 10.1039/c6ra26371b

rsc.li/rsc-advances

\section{Effects of composition and structure on the performance of tin/graphene-containing carbon nanofibers for Li-ion anodes $\uparrow$}

\begin{abstract}
Martin K. Dufficy, Sheng-Yang Huang, Saad A. Khan and Peter S. Fedkiw*
Tin is a promising replacement for graphite anodes in Li-ion batteries (994 $\mathrm{mA} \mathrm{h} \mathrm{g}^{-1}$ for Sn vs. $372 \mathrm{~mA} \mathrm{~h} \mathrm{~g}^{-1}$ for graphite), but suffers from particle pulverization upon lithiation that causes capacity fade. Herein, thermally reduced graphene oxide-containing carbon nanofibers (TRGO/CNFs) are used as scaffolds to house $\mathrm{Sn} / \mathrm{SnO}_{2}$ particles, enhance anode capacity beyond that of graphite, and prolong cycle life of Snbased electrodes. This study attempts to elucidate structure-composition relationships of tin-TRGO/ CNF electrodes that lead to increased capacity retention. The composition and morphology of tinTRGO/CNFs are assessed as a function of heat-treatment temperature and Sn loading as a means to understand and correlate electrochemical performance with physical features. We find: (1) the oxidation state of tin in TRGO/CNFs is in part determined by temperature-dependent, thermal-decomposition products of polyacrylonitrile-derived CNFs, and (2) precursor Sn(Iv) loadings $\leq 10 \mathrm{wt} \%$ in the tin-TRGO/ $\mathrm{CNFs}$ lead to $\mathrm{Sn}(0)$ or $\mathrm{SnO}_{2}$ particles embedded within the fiber + TRGO matrix. Electrodes with precursor Sn(Iv) loading $\leq 10$ wt\% have smaller tin particles than electrodes with Sn(Iv) loadings $>10$ wt\%, and have longer cycle-lives; reversible capacities of $\sim 600 \mathrm{~mA} \mathrm{~h} \mathrm{~g}^{-1}$ are observed at $0.2 \mathrm{C}$ rates, while capacities of $\sim 400 \mathrm{~mA} \mathrm{~h} \mathrm{~g}^{-1}$ are observed after hundreds of cycles at $2 \mathrm{C}$ rates. The durable graphenecontaining nanofiber matrix, coupled with the high-capacity of tin, provides a promising anode material for Li-ion cells.
\end{abstract}

\section{Introduction}

Advancements in mobile technology require electrochemical energy storage devices with an energy and power density beyond that of current Li-ion batteries. Enhanced Li-ion battery performance may be achieved with new active materials that exhibit charge capacities beyond carbon. ${ }^{\mathbf{1 - 3}}$ Tin is an attractive anode material with a large theoretical charge capacity (994 $\mathrm{mA} \mathrm{h} \mathrm{g}^{-1}, 1990 \mathrm{~mA} \mathrm{~h} \mathrm{~cm}^{-3}$ ), but suffers from particle pulverization due to catastrophic mechanical strain at full lithiation. ${ }^{4}$ Pulverization results in electronic isolation-caused by recurrent solid-electrolyte interphase (SEI) formation-and a short cycle life. One proposed method to cope with the strain of Liinsertion is to form composite tin materials, such as tin alloys or Sn/C materials. A battery using tin alloy anodes, introduced by Sony under the name Nexelion, ${ }^{\mathbf{5 , 6}}$ saw limited success due to capacity fade and short cycle life. Another common method to cope with the frail $\mathrm{Sn}-\mathrm{Li}$ complex is to use the oxide of tin. Fuji introduced batteries with tin-composite oxide anodes under the name Stalion, ${ }^{7}$ which never reached commercialization due to

Department of Chemical and Biomolecular Engineering, North Carolina State University, Raleigh, NC, USA 27695.E-mail: Fedkiw@ncsu.edu

$\dagger$ Electronic supplementary information (ESI) available. See DOI: 10.1039/c6ra26371b its large capacity fade. Thus, new methods to extend the cyclelife of tin-based anodes are a worthy research thrust. Herein, we report upon tin/carbon composites as a means to enhance Sn-based anode cycle life.

Carbon composites have long been a common method to enhance electrode cycle life. ${ }^{8}$ Moreover, carbon nanofibers (CNFs) provide a favorably-sized support for composite electrodes for fast Li-diffusion and high-rate capabilities. ${ }^{9}$ CNFs are also durable materials, and thus composite materials (e.g., Sn particles) may impart strains to the CNF matrix during volume expansions to inhibit pulverization; volume expansions in the $\mathrm{LiC}_{x}$ complex are small ( $\sim 10 \%$ graphene layer expansion) relative to the $\mathrm{Li}_{x} \mathrm{Sn}$ complex ( $\sim 300 \%$ volume expansion). ${ }^{10}$ The CNF electrode is well characterized, ${ }^{\mathbf{1 1}, \mathbf{1 2}}$ and long cycle lives have been reported ${ }^{\mathbf{1 3}}$ with use of CNF anodes produced via electrospinning. The nonwoven carbon architecture from electrospinning negates the need for binder and conductive additive, ${ }^{\mathbf{1 4 , 1 5}}$ which enhances electrode gravimetric energy density.

We recently demonstrated that thermally reduced graphene oxide-containing carbon nanofibers (TRGO/CNFs) increase charge capacity and electronic conductivity compared to CNFs. ${ }^{16}$ As a continuation of our investigation of TRGO/CNFs anodes for LIBs, we study composite CNFs as a matrix for embedding $\mathrm{Sn}$ or $\mathrm{SnO}_{2}$ particles to produce $\mathrm{Sn}$ - or $\mathrm{SnO}_{2}$ - 
containing TRGO/CNF electrodes. While Sn-containing CNFs have been applied to LIB anodes, ${ }^{\mathbf{1 2 , 1 4 - 1 6}}$ such studies frequently highlight the electrochemical cycling behavior and minimize importance of structure evolution. Studies on production of $\mathrm{Sn}$ or $\mathrm{SnO}_{2} / \mathrm{C}$ composites from precursors such as $\mathrm{SnCl}_{4}$ and polyacrylonitrile (PAN, a common CNF precursor) do not discuss simultaneous $\mathrm{Sn}$ (II) or (Iv) reduction and the carbonization process. Additionally, to our knowledge, the influence of tin loading on fiber morphology has not been reported. Herein, we report the formation and evolution of Sn-TRGO/CNFs electrodes; we explore the influence of heat-treatment temperature (HTT) on Sn oxidation state, and the influence of Sn-precursor concentration on particle size after heat treatment. We relate physical parameters favorable for LIB electrodes (composition, morphology, Sn-particle size, etc.) to electrochemical half-cell cycling performance. The $\mathrm{SnO}_{2}$-based electrodes produced in this work revealed capacities $\sim 400 \mathrm{~mA} \mathrm{~h} \mathrm{~g}^{-1}$ after 900 cycles at $2 \mathrm{C}$ rates, and $\mathrm{Sn}$-based electrodes revealed similar capacities $\sim 400 \mathrm{~mA} \mathrm{~h} \mathrm{~g}^{-1}$ after 500 cycles at $2 \mathrm{C}$ rates. Long-cycle lives are ascribed to preservation of TRGO/CNF structure, which withstands structural rearrangement of Sn during Li-insertion. This study shows $\mathrm{Sn}$ and $\mathrm{SnO}_{2}-\mathrm{TRGO} / \mathrm{CNF}$ is promising electrode material for Li-ion cells.

\section{Experimental}

\subsection{Preparation of electrospinning solution}

Appropriate amounts of $\mathrm{SnCl}_{4}$ (Sigma Aldrich, 99.995\%) were added to anhydrous dimethylformamide (DMF, Sigma Aldrich, 99.8\%) in an argon-filled glove box, such that Sn(Iv) content in dry polymer fibers comprised $0,5,10,15$, or $30 \mathrm{wt} \%$. Anhydrous ethylene glycol (Sigma Aldrich, 99.8\%) was added to the $\mathrm{SnCl}_{4} /$ DMF mixture in a ratio of $4: 1 \mathrm{~mol}$ ethylene glycol : $\mathrm{SnCl}_{4}$. Graphite oxide ${ }^{16}$ was then added to the solution, resulting in a loading of $5 \mathrm{wt} \%$ relative to dry polymer-fiber content. The mixture was sealed, taken out of the glove box, and sonicated for 1 hour to exfoliate graphite oxide into single-to-multilayer graphene oxide (GO) sheets. After sonication, polyacrylonitrile (PAN, Scientific Polymer Products, $150 \mathrm{kDa}$ ) was added to the dispersion in ambient conditions, resulting in an $8 \mathrm{wt} \%$ polymer solution, and stirred overnight at $60^{\circ} \mathrm{C}$.

\subsection{Preparation of Sn-containing fibers}

The electrospinning precursor solution was cooled to room temperature and then electrospun using a needle-and-plate collector system, as described elsewhere. ${ }^{17}$ Typical process parameters include flow rate, voltage, tip-to-collector plate distance, and relative humidity of $1 \mathrm{~mL} \mathrm{~h}^{-1}, 5-7 \mathrm{kV}, 17 \mathrm{~cm}$, and $50-60 \%$, respectively. Composite polymer fibers amassed in a nonwoven mat on an Al-foil collector to create Sn-GO/PAN fibers. The mats were thermally treated in a quartz tube furnace using a two-step process. The first thermal treatment, stabilization, was conducted under dry air at $275^{\circ} \mathrm{C}$ for 2 hours, using a heating ramp rate of $5{ }^{\circ} \mathrm{C} \mathrm{min}^{-1}$ followed by uncontrolled cooling to room temperature. The second heat treatment, carbonization, was conducted under nitrogen at 650 or
$850{ }^{\circ} \mathrm{C}$ using a heating rate of $2{ }^{\circ} \mathrm{C} \mathrm{min}^{-1}$, a dwell time of 1 hour at maximum temperature, and uncontrolled cooling to room temperature (typically 3 hours). The quartz furnace was purged with nitrogen for 3 hours prior to carbonization. The notation used to represent the electrodes produced in this study denotes precursor $\mathrm{Sn}$ (Iv) wt\% in the polymer fibers, followed by the carbonization temperature (in ${ }^{\circ} \mathrm{C}$ ). For example, a tin-GO/PAN solution electrospun with $10 \mathrm{wt} \% \mathrm{Sn}$ (Iv) and carbonized at $650{ }^{\circ} \mathrm{C}$ is denoted $10 \mathrm{Sn} 650$.

\subsection{Characterization of Sn-containing fibers}

Solution rheology was measured using an AR2000 (TA Instruments) stress-controlled rheometer with $40 \mathrm{~mm}$ diameter, parallel-plate geometry and a gap size of $100 \mu \mathrm{m}$. Ionic conductivity of the electrospinning precursor solution was measured using a Mettler Toledo S47-K conductivity meter. Scanning electron microscope (SEM) images were captured on a FEI Verios 460L XHR equipped with an energy-dispersive X-ray spectroscopy (EDS) detector. Polymer fibers were sputter coated with $4 \mathrm{~nm}$ of $\mathrm{Au} / \mathrm{Pd}$ alloy to increase conductivity before imaging. Fiber-diameter distributions were obtained by measuring diameters from SEM images of 100 fibers from three locations on a nonwoven mat. Transmission electron microscope (TEM) images were taken on a JEOL 2010F, which was also equipped with an EDS detector. To prepare samples on TEM grids, we first dispersed fiber mats in acetone followed by sonication for 1 hour. Thermogravimetric analysis (TGA) of composite-polymer fibers was conducted on a Discovery Series thermogravimetric analyzer (TA Instruments). Bulk structure analysis was measured on a Rigaku SmartLab X-ray diffractometer $(\mathrm{Cu} \mathrm{K} \alpha, \lambda=1.5406 \AA)$. Surface analysis of fibers was conducted on a SPECS X-ray photoelectron spectroscopy (XPS) unit equipped with a dual $\mathrm{Al} / \mathrm{Mg}$ anode monochromator source. The carbon transition (C 1s, $285 \mathrm{eV}$ ) was used to normalize the spectra. Samples were dried in a vacuum oven overnight at $100{ }^{\circ} \mathrm{C}$ prior to XPS analysis.

\subsection{Electrochemical characterization}

Carbonized mat working electrodes were punched into $1.11 \mathrm{~cm}$ diameter discs from the electrospun mat and dried in a vacuum oven overnight at $100{ }^{\circ} \mathrm{C}$. The discs were transferred to an argon-filled glove box. Carbonized mats (areal loading: $1-1.3 \mathrm{mg}$ $\mathrm{cm}^{-2}$ ) were placed on a $\mathrm{Cu}$ foil current collector and cycled against metallic Li (Sigma Aldrich, 99\%) in 2032 half-cells. The electrolyte, $1 \mathrm{M} \mathrm{LiPF}_{6}$ (>99\% purity, BASF) dissolved in ethylene carbonate (EC, 99\% purity, Sigma Aldrich) and ethyl methyl carbonate (EMC, 99\% purity, Sigma Aldrich) comprising a $1: 1$ $\mathrm{wt} \% \mathrm{EC}$ : EMC solution, was added by pipette onto the working electrode $(\sim 50 \mu \mathrm{L})$ and Celgard separator $(\sim 50 \mu \mathrm{L})$. Prior to use, the electrolyte was dried in $4 \AA$ molecular sieves (Sigma Aldrich) to a water content $<10 \mathrm{ppm}$. All half-cells underwent a formation cycle at $\mathrm{C} / 24$ prior to further cycling. Charge/discharge cycling and cyclic voltammetry (CV) was conducted on a BioLogic VMP3 between 2.5 and $0.01 \mathrm{~V}$ vs. $\mathrm{Li} / \mathrm{Li}^{+}$. Electrochemical measurements were conducted on at least 3 half-cells to assure reproducibility, typically within $10 \%$. 


\section{Results and discussion}

\subsection{Characterization of Sn-fibers}

Prior to thermal treatment, tin-polymer fibers were analyzed via SEM to observe fiber morphology (Fig. 1a-e). Images in Fig. 1 show (1) a continuous network of fibers with fiber beading at $\mathrm{Sn}$ (Iv) concentrations $>5 \mathrm{wt} \%$, and (2) fiber diameter increases with Sn-loading. As noted in our previous study, ${ }^{\mathbf{1 6}}$ the appearance of beads may be caused by encapsulated GO in the mats, which was added at $5 \mathrm{wt} \%$ to the fibers to increase the charge capacity and conductivity of CNFs. Additional electron microscope images, including TRGO/CNFs in the absence of tin, are available in our previous study. ${ }^{16}$ However, the beading observed at $>5 \mathrm{wt} \%$ Sn(Iv) loading (Fig. 1c-e) is not due to GO sheets, as evidenced by a different morphology than reported in our previous study on TRGO/CNFs in the absence of tin, ${ }^{\mathbf{1 6}}$ and may be attributed to decreased "effective" polymer concentration as filler content increased. We measured electrospinning precursor solution properties that govern the electrospinning process, such as solution rheology and ionic conductivity, in attempt to correlate fiber diameter and beading in the fibers with $\mathrm{Sn}$ (Iv) loading. Steady-shear rheology (Fig. S1†) of the electrospinning solution revealed viscosity (1) to be independent of $\mathrm{SnCl}_{4}$ concentration at high-shear stresses (or shear rates), and (2) to marginally increase with EG addition (added $4: 1 \mathrm{~mol}$ ratio EG : $\mathrm{SnCl}_{4}$ ). However, the increased viscosity we measured from EG addition $\left(<1 \mathrm{~Pa} \mathrm{~s}^{-1}\right.$ at high-shear stresses) is not significant to increase the fiber diameter. Interestingly, increasing $\mathrm{SnCl}_{4}$ concentration, and thus ionic conductivity (Fig. 1f), did not lead to smaller fiber diameters; it is generally accepted that increasing solution conductivity increases whipping instabilities of the polymer jet during electrospinning that reduces fiber diameter. ${ }^{18}$ Thus, we attribute the increase in fiber diameter to EG swelling in PAN; a larger EG content is associated with higher $\mathrm{SnCl}_{4}$ concentration. Insets of Fig. 1a-e show high-resolution images of a typical fiber extruded during the electrospinning process. The fibers produced are porous, which may be the result of volatilized solvent.

Thermally treating (stabilization and carbonization) tin-GO/ PAN fibers (to produce $\mathrm{Sn}$ - or $\mathrm{SnO}_{2}$-TRGO/CNFs) decreased diameters to values independent of Sn(Iv) loading (Fig. S2 $\dagger$ ); the average fiber diameter ranged from 340 to $470 \mathrm{~nm}$ at $650{ }^{\circ} \mathrm{C}$ and 280 to 330 at $850{ }^{\circ} \mathrm{C}$, but fiber diameter did not systematically increase with $\mathrm{Sn}$ (Iv) loading. The diameter distributions (Fig. S2 $\dagger$ ) suggest EG swelled PAN to increase fiber size, as unevaporated
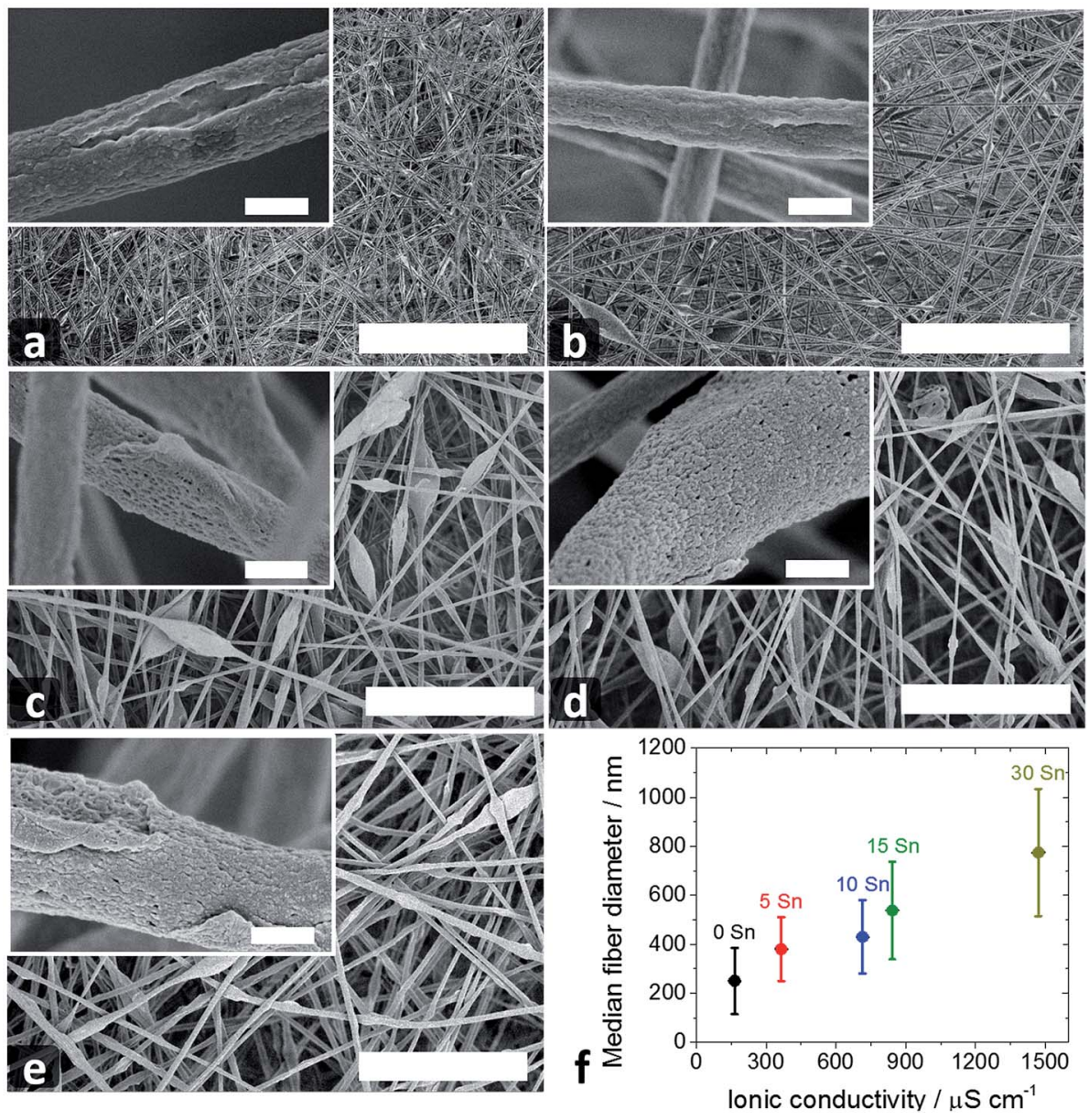

Fig. 1 SEM images of nonwoven GO/PAN mats with (a) 0, (b) 5, (c) 10, (d) 15, and (e) 30 wt\% Sn(Iv). The scale bars represent $20 \mu \mathrm{m}$. The insets show high-resolution SEM images of a typical fiber. Scale bars of insets represent $500 \mathrm{~nm}$; (f) fiber diameter plotted against ionic conductivity of electrospinning solution, with Sn(Iv) loading [wt\%] labeled on the plot. 
EG generated larger resistances to whipping instabilities during electrospinning. Heat treatments also collapsed large pores (Fig. 1a-e inset), although it is possible that heat-treated fibers retain a porous structure too small to discern in the SEM images.

As apparent by SEM, tin-TRGO/CNFs carbonized at $650{ }^{\circ} \mathrm{C}$ produced similar morphologies, irrespective of $\mathrm{Sn}(\mathrm{Iv})$ loading (Fig. S3†); we did not observe sintering or agglomeration of tin despite carbonization temperatures above the melting point of $\mathrm{Sn}\left(232^{\circ} \mathrm{C}\right)$. Increasing carbonization temperature from 650 to $850{ }^{\circ} \mathrm{C}$ and $\mathrm{Sn}$ (Iv) loadings $>5 \mathrm{wt} \%$ produced $\mathrm{Sn}$ particles on the fiber surface (Fig. 2). Loadings of $5 \mathrm{wt} \% \mathrm{Sn}$ (Iv) (Fig. 2a and b) produced fibers with a morphology similar to fibers in the absence of tin (Fig. S4 $\dagger$ ), suggesting that small Sn particles, not discernable at the magnifications employed, are present. An increased loading of $10 \mathrm{wt} \% \mathrm{Sn}$ (Iv) effected sparsely-decorated Sn particles on fibers (Fig. 2c and d), however the majority of Sn appeared to be within the TRGO/CNF scaffolding. Sn(Iv) loadings $>10 \mathrm{wt} \%$ produced fibers with abundant, large particles on the fiber surface. Mean Sn particle diameters of 830 and $330 \mathrm{~nm}$ were observed with 15 (Fig. 2e and f) and $30 \mathrm{wt} \% \mathrm{Sn}$ (Iv) (Fig. $2 \mathrm{~g}$ and $\mathrm{h}$ ), respectively. Similar Sn-aggregation has recently been reported with $\mathrm{Sn}(\mathrm{Iv})$ heat treated at $700{ }^{\circ} \mathrm{C} .{ }^{19}$

Heat treatments of tin-GO/PAN fibers likely produced temperature-dependent gaseous atmospheres, leading to unique fiber morphologies (previously seen in SEM images) and tin oxidation states. Carbonization of PAN releases gases such as $\mathrm{H}_{2}, \mathrm{HCN}, \mathrm{NH}_{3}$, and $\mathrm{CH}_{4},{ }^{20,21}$ and evolution of particular gases during carbonization is temperature dependent. ${ }^{21}$ It has been proposed that $\mathrm{H}_{2}$ off-gasses (producing a reducing atmosphere) at $\sim 900{ }^{\circ} \mathrm{C}^{21}$ as a product of reactions between hydrogenated carbons and nitrogen molecules in cyclic compounds, whereas $\mathrm{N}_{2}$ off-gasses at $600{ }^{\circ} \mathrm{C}$ as a product of reactions between cyclic nitrogen compounds. We observed evidence of these two reactions (releasing $\mathrm{H}_{2}$ and $\mathrm{N}_{2}$ ) via derivative thermogravimetric analysis (DTG) of PAN fibers (Fig. S5 $\dagger$ ). DTG plots produced a broad peak at $\sim 650{ }^{\circ} \mathrm{C}$ with a shoulder appearing at $850{ }^{\circ} \mathrm{C}$, which likely corresponded to thermal decomposition of PAN releasing $\mathrm{N}_{2}$ and $\mathrm{H}_{2}$, respectively. We propose that $\mathrm{H}_{2}$ is a major PAN-decomposition product at $850{ }^{\circ} \mathrm{C}$, facilitating the carbothermic reduction of $\mathrm{Sn}$ (Iv) to $\mathrm{Sn}(0)$ and agglomeration of metallic Sn (as seen in Fig. 2c and d). Such a mechanism is likely, as researchers ${ }^{22}$ have shown that $\mathrm{SnO}_{2}$ reduces to $\mathrm{Sn}(0)$ at temperatures as low as $450{ }^{\circ} \mathrm{C}$ in a $\mathrm{H}_{2}$ atmosphere. In contrast, $\mathrm{N}_{2}$ comprised the majority of decomposition gases released at $650{ }^{\circ} \mathrm{C}$, resulting in $\mathrm{SnO}_{2}$ particles in TRGO/CNFs. Sn-O bonds form via condensation reaction between $\mathrm{SnCl}_{4}$ and $\mathrm{EG}$, releasing $\mathrm{HCl}^{23}$ Thermal treatment then decomposed Sn-EG entities to $\mathrm{SnO}_{2}$.

We employed XPS on tin-GO/PAN fibers and tin-TRGO/CNFs carbonized at 650 and $850{ }^{\circ} \mathrm{C}$ in an attempt to detect the presence of contaminants such as $\mathrm{Cl}$, observe polymer degradation through the nitrogen signal, and identify tin oxidation state. Fibers with 10 wt $\%$ Sn(Iv) loading were analyzed. Chlorine (4 : $1 \mathrm{~mol} \mathrm{Cl} \mathrm{:} \mathrm{Sn} \mathrm{in} \mathrm{precursor)} \mathrm{was} \mathrm{not} \mathrm{detected} \mathrm{on} \mathrm{survey} \mathrm{scans}$ (Fig. 3a), and produced weak signals on the $\mathrm{Cl} 2 \mathrm{p}$ transition (Fig. S6a $\dagger$ ). Absence of $\mathrm{Cl}$ from the survey of as-spun fibers suggests a surface $(<10 \mathrm{~nm})$ relatively free of $\mathrm{Cl}$ or $\mathrm{HCl}$ (product from condensation of $\mathrm{SnCl}_{4}$ and EG). The XPS survey also shows decreasing $\mathrm{N}$-content in the fibers, from 22 to 15 to $8 \mathrm{wt} \% \mathrm{~N}$ in as-spun fibers, and fibers heat-treated at 650 and $850{ }^{\circ} \mathrm{C}$, respectively, as PAN thermally degrades into a carbon-rich structure. We observed slightly lower binding energies than expected in the $\mathrm{N}$ 1s transition (Fig. S6b $\dagger$ ) of tin-TRGO/CNFs, which may be due to metal-nitride $(\mathrm{Sn}-\mathrm{N})$ formation, as reported elsewhere. ${ }^{24} \quad$ Nonetheless, nitrogen-containing compounds in large quantities are undesired, ${ }^{25}$ as they may result in the irreversible formation of LiN during LIB charge cycles and decrease capacity retention. Interestingly, Sn $3 \mathrm{~d}_{5 / 2}$ (Fig. 3b) peaks in as-spun mats shifted positive $\sim 1 \mathrm{eV}$ upon carbonization, which suggests formation of the oxide $\left(\mathrm{SnO}_{2} \sim\right.$ 486.5-486.7 eV). As previously stated, Sn-O bonds initially formed in as-spun mats via a reaction between $\mathrm{SnCl}_{4}$ and EG. Lower binding energies in as-spun fibers may be due, in part, to remaining $\mathrm{Sn}-\mathrm{Cl}$ linkages. Broad $\mathrm{Sn} 3 \mathrm{~d}$ peaks from fibers carbonized at 650 and $850{ }^{\circ} \mathrm{C}$ are similar, and we were unable to distinguish if the open-air environment prior to XPS analysis resulted in (1) formation of a native-surface oxide layer on large $\mathrm{Sn}(0)$ particles, or (2) complete oxidation of small $\mathrm{Sn}(0)$ particles
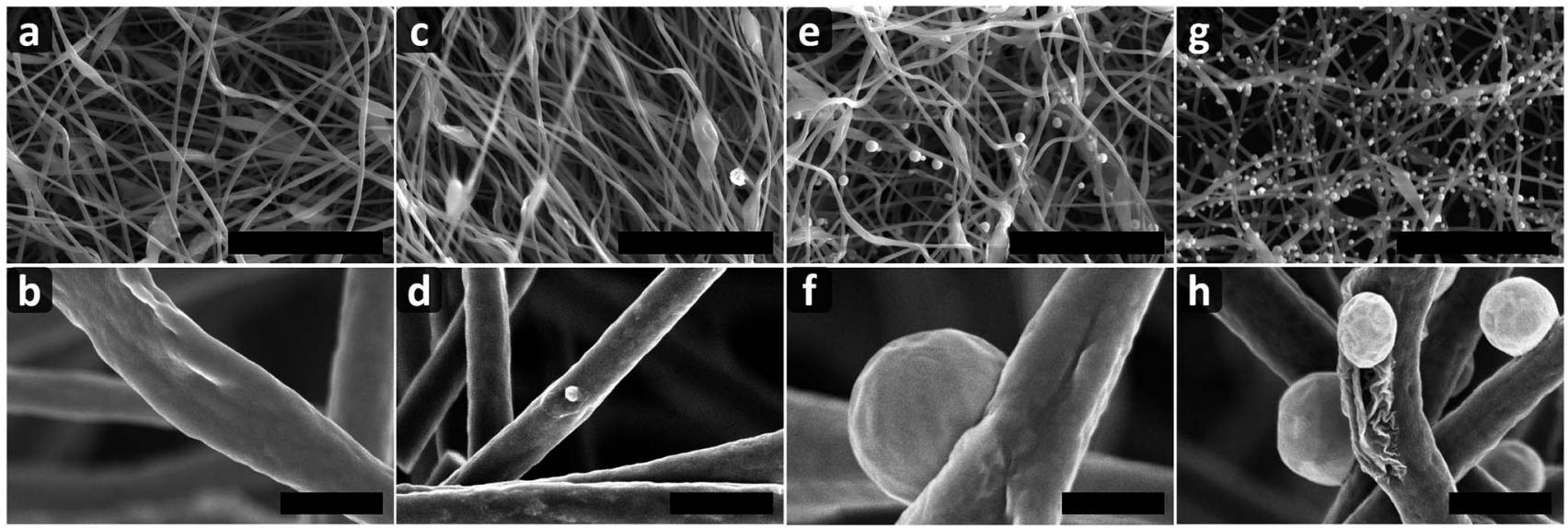

Fig. 2 SEM images of TRGO/CNFs carbonized at $850^{\circ} \mathrm{C}$ with (a, b) 5, (c, d) 10, (e, f) 15, and (g, h) 30 wt\% Sn(Iv). Scale bars represent (a, c, e, and g) $10 \mu \mathrm{m}$ and $(b, d, f$, and h) $500 \mathrm{~nm}$. 

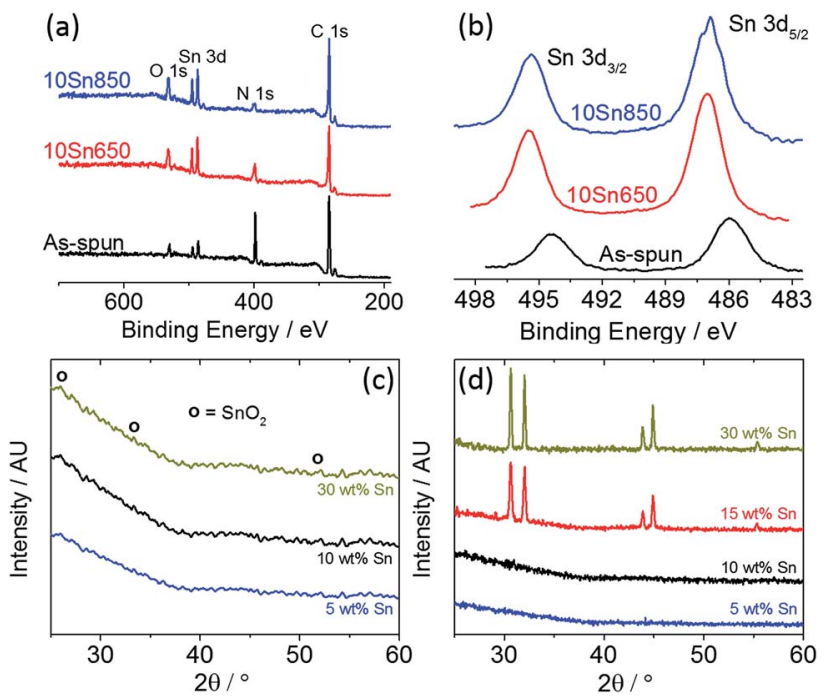

Fig. 3 Surface and bulk characterization of Sn-containing fibers; XPS data of as-spun GO/PAN fibers containing $10 \mathrm{wt} \% \mathrm{Sn}(\mathrm{Iv})$, along with the ensuing spectra of fibers carbonized at 650 and $850{ }^{\circ} \mathrm{C}$ showing (a) the survey and (b) high-resolution Sn $3 d$ transition. XRD profiles for tinTRGO/CNFs carbonized at (c) $650^{\circ} \mathrm{C}$ and (d) $850{ }^{\circ} \mathrm{C}$ with $\mathrm{Sn}$ loadings labeled on the plot. If present, the location of the strongest peaks associated with $\mathrm{SnO}_{2}$ are labeled in (c).

near the fiber surface to create $\mathrm{SnO}_{2}$ particles. We employed $\mathrm{XRD}$ in attempt to make this distinction.

Composite tin fibers carbonized at $650{ }^{\circ} \mathrm{C}$ produced $\mathrm{X}$-ray diffraction patterns independent of tin loading without discernible diffraction signatures from $\mathrm{Sn} / \mathrm{SnO}_{2}$ (Fig. 3c), presumably due to the small size or amorphous nature of tin. We note that crystalline $\mathrm{SnO}_{2}$ may be present in the form of small particles that do not generate diffraction patterns. Likewise, TRGO/CNFs carbonized at $850{ }^{\circ} \mathrm{C}$ with $\leq 10 \mathrm{wt} \% \mathrm{Sn}$ (Iv) did not produce diffraction patterns (Fig. 3d). Although large (and sparsely dispersed) particulates were observed in SEM images of $10 \mathrm{Sn} 850$ (Fig. 2d), the sensitivity of XRD was insufficient to register a diffraction signal. The diffractions pattern of fibers with loadings $\leq 10 \mathrm{wt} \% \mathrm{Sn}$ (Iv) displayed the amorphous (002) phase of TRGO/CNFs ( $2 \theta \approx 25^{\circ}$, not shown), as we described elsewhere. ${ }^{16}$ Greater than $10 \mathrm{wt} \% \mathrm{Sn}$ (Iv) loading formed crystalline structures of metallic Sn (Fig. 3d); the peaks are associated with the large Sn particles that were observed via SEM. Thus, it is reasonable to infer that $\mathrm{H}_{2}$ off-gassing occurred during the carbonization process to reduce $\mathrm{Sn}(\mathrm{Iv})$ to $\mathrm{Sn}(0)$.

In an attempt to detect $\mathrm{Sn}(0)$ or $\mathrm{SnO}_{2}$ particles that were not found with XRD (e.g., fibers with low, $\leq 10 \mathrm{wt} \%$, Sn(Iv) loading), we examined heat-treated fibers under high-resolution TEM. As expected, tin-TRGO/CNFs heat-treated at $650{ }^{\circ} \mathrm{C}$ did not contain crystalline particles; we merely observed the amorphous $\mathrm{Sn} / \mathrm{C}$ structure (Fig. 4a). On the other hand, tin-TRGO/CNFs carbonized at $850{ }^{\circ} \mathrm{C}$ contained crystalline particles of $\mathrm{SnO}_{2}$ that were visible near the fiber surface (Fig. 4b). Particulates near the fiber surface may originate from the mobility of low-molecular weight Sn-EG entities, which migrate to the air-fiber interface during heat treatments. Particles encapsulated within a fiber matrix are favorable for LIB cycling, as they may impart stresses onto the TRGO/CNF scaffolding during volume expansions of lithiation to minimize cracking. Measurements of lattice fringes confirmed presence of $\mathrm{SnO}_{2}$ (JCPDS 41-1445) within TRGO/ CNFs carbonized at $850{ }^{\circ} \mathrm{C}$, with a particle size $<15 \mathrm{~nm}$. Particles of $\mathrm{SnO}_{2}$ also appeared on TRGO that was protruding through the fiber surface (Fig. 4c). In addition to the roles of TRGO in composite CNF synthesis described in our previous study, ${ }^{\mathbf{1 6}}$ here we note the presence of tin particles on TRGO (or within few layers) may originate from hydrogen bonding interactions between terminal hydroxyl groups of EG-Sn entities and oxygen functional groups of GO in the electrospinning solution. Appearance of $\mathrm{SnO}_{2}$ on TRGO/CNFs with $10 \mathrm{wt} \% \mathrm{Sn}(\mathrm{Iv})$ and carbonized at $850{ }^{\circ} \mathrm{C}$ was not expected since we detected $\operatorname{Sn}(0)$ on TRGO/CNFs with $>10 \mathrm{wt} \% \mathrm{Sn}$ (Iv) and carbonized at $850{ }^{\circ} \mathrm{C}$ using XRD. However, we note that TEM sample preparation (exposure to air and sonication in acetone, which heats the sample to $\sim 45{ }^{\circ} \mathrm{C}$ ) likely oxidized small $\mathrm{Sn}(0)$ particles on or near the TRGO/CNF surface to $\mathrm{SnO}_{2}$.

Well-dispersed tin-particulates in the anode presumably leads to uniform stress during lithiation and hinders regions of disproportionate stress that may lead to electrode cracking. Thus, a uniform Sn-particle dispersion is necessary to extend the cycle life of high-capacity anodes. We used EDS to determine the dispersion of tin within tin-TRGO/CNF fibers. Fig. 4d shows typical EDS maps (acquired via STEM imaging) for 10 Sn650. Regions of Sn appear dispersed throughout many fibers on the EDS image, however Sn-rich regions throughout all fibers could not be resolved (in a manner similar to element maps of carbon and oxygen) due to curvature of the fibers, shadowing effects, and focal plane of the image. It should be noted that a small amount of Cl was observed via EDS, which produced a negligible peak $\sim 2.6 \mathrm{keV}$ in the EDS spectrum (Fig. S7b $\dagger$ ). Coupling EDS and XPS data suggest a $\mathrm{Cl}$ content in tin-TRGO/CNFs $<0.2 \mathrm{wt} \%$. Typical EDS maps of tin-TRGO/CNFs at $850{ }^{\circ} \mathrm{C}$ are shown in Fig. S7 and S8. $\uparrow$ Tin also appeared well-dispersed in TRGO/CNFs carbonized at $850{ }^{\circ} \mathrm{C}$ and at low $\mathrm{Sn}$ (Iv) loadings ( $\leq 10 \mathrm{wt} \%$ ), while larger tin loadings produced EDS maps with tin appearing both on large aggregated particles and dispersed throughout the fiber-not all tin aggregated into large $\operatorname{Sn}(0)$ particles. Interestingly, we found that EDS maps of Sn and N overlapped (Fig. S7a $\dagger$ ). Overlapping Sn and N EDS maps, coupled with XPS data (Fig. S6b $\dagger$ ) that show $\mathrm{N}$ 1s transitions at more negative binding energies than expected for $\mathrm{Sn} / \mathrm{C}$ composites, may indicate formation of tin nitride upon thermal treatments. Tin nitride is produced via thermal treatment of $\mathrm{Sn}(\mathrm{IV})$ with $\mathrm{NH}_{3}$ and $\mathrm{N}_{2}$ gases ${ }^{26,27}$ and may exist in small quantities in the fibers since $\mathrm{NH}_{3}$ and $\mathrm{N}_{2}$ are products of PAN carbonization. The lack of $\mathrm{Sn}_{x} \mathrm{~N}_{y}$ peaks on XRD suggests that small, amorphous regions of $\mathrm{Sn}_{x} \mathrm{~N}_{y}$ may exist. While reports suggest that nitrogen-doped carbons ${ }^{\mathbf{2 8 , 2 9}}$ (and perhaps doping Sn in the process) leads to enhanced cycling, to our knowledge the electrochemical performance of tin nitride has not been assessed.

\subsection{Electrochemical characterization of Sn-containing fibers}

Since we were unable to conclusively deduce the oxidation state of tin within fibers heat-treated at $650^{\circ} \mathrm{C}$ and $\mathrm{Sn}$ (Iv) loadings $<15$ 

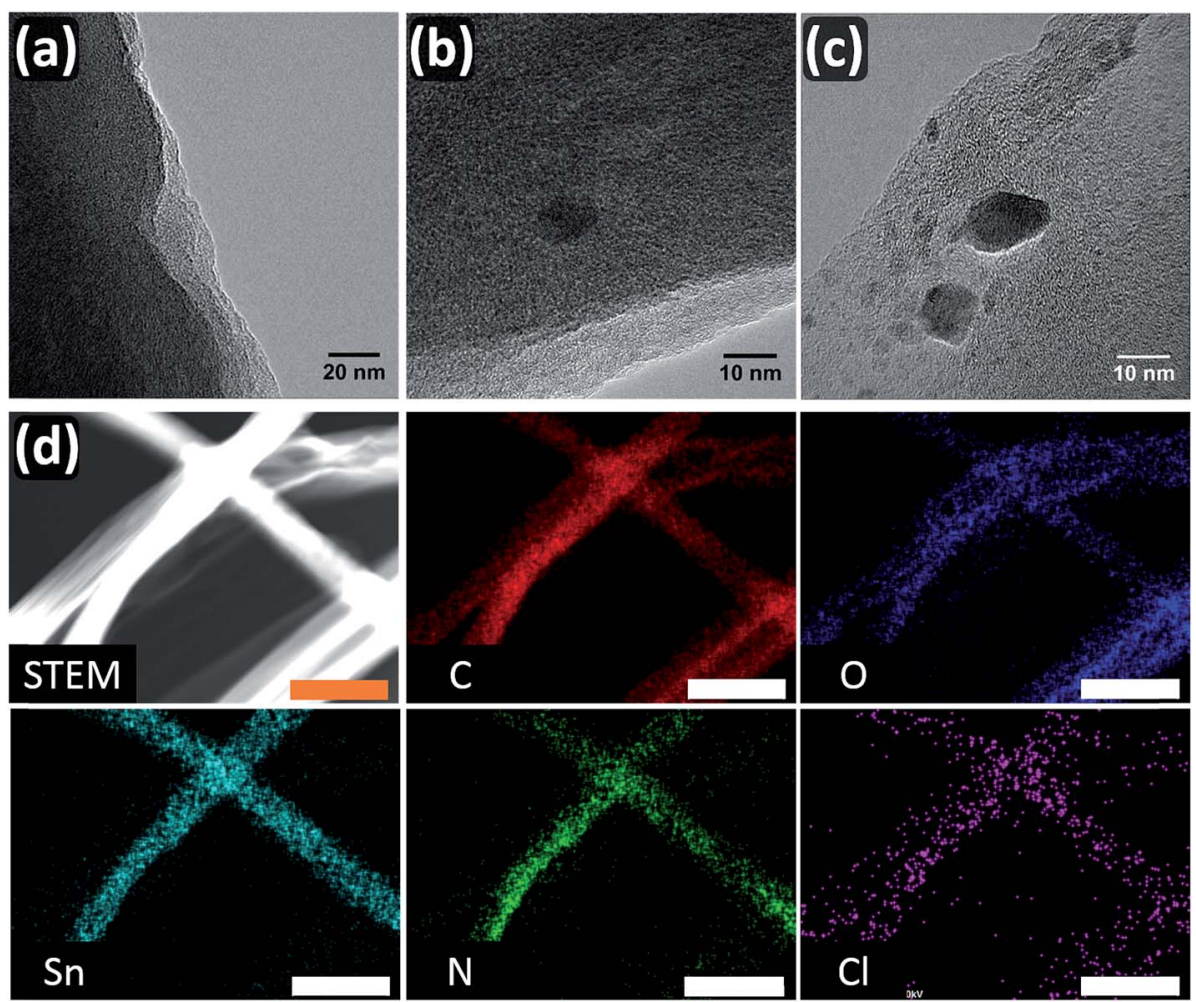

Fig. 4 TEM images of (a) $10 S n 650$ (b, c) 10 Sn850 (d) STEM image and corresponding EDS maps of 10Sn650. The element pertaining to each map is labeled in the lower left. Scale bars for EDS represent $1 \mu \mathrm{m}$.

wt $\%$ in fibers heat-treated at $850{ }^{\circ} \mathrm{C}$ using physical characterization methods, we employed $\mathrm{CV}$ as an electrochemical means to study composition of tin in the fibers. Working electrodes consisted of $10 \mathrm{Sn} 650$ and $10 \mathrm{Sn} 850$, identical to samples analyzed via XPS and TEM. Voltammograms of tin-TRGO/CNFs carbonized at $650^{\circ} \mathrm{C}$ indicate presence of $\mathrm{SnO}_{2}$ on the first cycle. The first cathodic polarization (Fig. 5a) scan shows two peaks: (1) irreversible reduction of $\mathrm{SnO}_{2}$ (Reaction (1)) and electrolyte reduction causing SEI formation at $\sim 0.7 \mathrm{~V} v s$. $\mathrm{Li}^{-\mathrm{Li}^{+}}$, and (2) three overlapping peaks from SnO reduction (Reaction (2)), ${ }^{30}$ Sn-Li complexation (Reaction (3)), and Li-intercalation into carbon (until $0.01 \mathrm{mV}$ ). The irreversible nature of $\mathrm{SnO}_{2}$ reduction is exemplified via $\mathrm{CV}$, as the high-voltage reduction peak does not appear on the second cathodic cycle.

$$
\begin{gathered}
\mathrm{SnO}_{2}+2 \mathrm{Li}^{+}+2 \mathrm{e}^{-} \rightarrow \mathrm{SnO}+\mathrm{Li}_{2} \mathrm{O} \\
\mathrm{SnO}+2 \mathrm{Li}^{+}+2 \mathrm{e}^{-} \rightarrow \mathrm{Sn}+\mathrm{Li}_{2} \mathrm{O} \\
\mathrm{Sn}+4.4 \mathrm{Li}^{+}+4.4 \mathrm{e}^{-} \underset{\text { discharge }}{\stackrel{\text { charge }}{\rightleftharpoons}} \mathrm{Li}_{4.4} \mathrm{Sn}
\end{gathered}
$$

Unlike the voltammogram of 10Sn650, the first-cycle cathodic polarization of the $10 \mathrm{Sn} 850$ sample (Fig. 5b) did not produce a broad peak at $0.7 \mathrm{~V} v s$. $\mathrm{Li}^{-\mathrm{Li}^{+}}$related to $\mathrm{SnO}_{2}$ reduction, which suggests the presence of $\operatorname{Sn}(0)$. Oxidized tin in TRGO/CNFs carbonized at $8500^{\circ} \mathrm{C}$ (native surface oxide layers or $\mathrm{SnO}_{2}$ particles near the electrode surface) did not contribute to appreciable reduction activity in the voltammograms. Thus, we

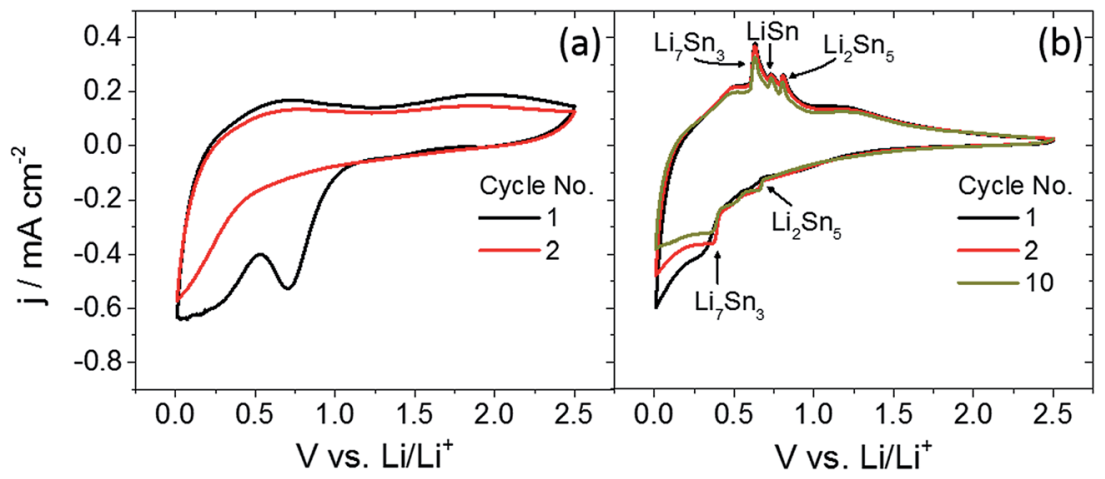

Fig. 5 Typical CV profiles using scan rates of $0.1 \mathrm{mV} \mathrm{s}^{-1}$ for (a) $10 \mathrm{Sn} 650$ and (b) $10 \mathrm{Sn} 850$ with phase transitions labeled. ${ }^{31}$ 
infer the majority of tin in the fibers carbonized at $650{ }^{\circ} \mathrm{C}$ and $850{ }^{\circ} \mathrm{C}$ resides in the oxide and metallic state, respectively. Distinct phase transitions ${ }^{31}$ in CV scans (labeled on Fig. 5b) are present over 10 cycles. Reoccurrence of redox peaks over cycling suggest that the TRGO/CNF support provides stability for small Sn particles, and prevents catastrophic cracking of the frail $\mathrm{Li}-$ Sn complex. Broad peaks at $\sim 1.2 \mathrm{~V}$ vs. $\mathrm{Li} / \mathrm{Li}^{+}$during anodic polarization of $\mathrm{Sn}$ - and $\mathrm{SnO}_{2}$-based electrodes have been attributed to partial oxidation of $\operatorname{Sn}(0)$ particles with diameters on the order of $1 \mathrm{~nm} \cdot{ }^{32,33}$ For comparison, voltammograms of TRGO/CNFs in the absence of tin produced similar peaks at $1.2 \mathrm{~V}$ vs. $\mathrm{Li} / \mathrm{Li}^{+}$with reduced magnitude (Fig. $\mathrm{S} 9 \dagger$ ). Thus, we attribute minimal activity to the oxidation of $\operatorname{small} \operatorname{Sn}(0)$ particles. The influence of tin oxidation state in TRGO/CNFs and fiber morphology on Li-ion half-cell cycling was subsequently evaluated.

Prior to galvanostatic cycling, we approximated the specific theoretical (calculated) capacities. Theoretical capacities were approximated using Sn composition from EDS analysis (such that specific capacities accounted for entire mat weight) with the following equation:

$$
\begin{aligned}
& \text { Capacity }_{\max } \approx\left(1000 \mathrm{~mA} \mathrm{~h} \mathrm{~g}^{-1}\right)\left(x \mathrm{wt}^{\circ} \% \mathrm{Sn}\right) \\
&+\left(375 \mathrm{~mA} \mathrm{~h} \mathrm{~g}^{-1}\right)\left(1-x \mathrm{wt}^{0} \mathrm{Sn}\right)
\end{aligned}
$$

Theoretical capacities, Sn concentration from EDS, and experimentally found, first-cycle lithiation capacities (using symmetrical constant current cycling at $0.05 \mathrm{C}$ rates) are listed in Table 1 . As a reminder, tin loadings in sample nomenclature are expressed in wt $\%$ of $\mathrm{Sn}(\mathrm{Iv})$ in GO/PAN polymer fibers. Actual Sn content in heat treated fibers approximately doubles. For example, 10 Sn 650 and $10 \mathrm{Sn} 850$ contain $\sim 20$ and $21 \mathrm{wt} \% \mathrm{Sn}$, respectively.

On the first lithiation cycle at $0.05 \mathrm{C}$, working electrodes carbonized at $650{ }^{\circ} \mathrm{C}$ exhibited capacities larger than calculated. For example, 5Sn650 electrodes displayed a capacity of 1465

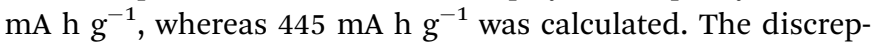
ancy is largely due to irreversible reduction of oxygen and nitrogen-containing entities (forming $\mathrm{Li}_{3} \mathrm{~N}$ and $\mathrm{Li}_{2} \mathrm{O}$ ) such as the electrochemical reduction of $\mathrm{SnO}_{2}$, as well as SEI formation. Reaction (1)-(3) produce a theoretical charge capacity of 1494 $\mathrm{mA} \mathrm{h} \mathrm{g}^{-1}$, which is larger than the capacity from Reaction (3) $\left(\sim 1000 \mathrm{~mA} \mathrm{~h} \mathrm{~g}^{-1}\right)$ that we used to determine theoretical capacities for $\mathrm{SnO}_{2}$-TRGO/CNFs. In contrast, Sn-TRGO/CNF electrodes heat treated at $850{ }^{\circ} \mathrm{C}$ exhibited first-cycle capacities closer to, but still greater than, calculated values (largely due to SEI formation). The thermal reduction of $\mathrm{SnO}_{2}$ to $\mathrm{Sn}$ during carbonization of PAN at $850{ }^{\circ} \mathrm{C}$ nullifies much of the irreversible capacity from Reaction (1) and (2) on the first cycle. Increasing the carbonization temperature from 650 to $850{ }^{\circ} \mathrm{C}$ produced higher coulombic efficiencies (Table 1), which we attribute to a more reduced electrode with less noncarbonaceous content; weight ratios of active $(\mathrm{C}+\mathrm{Sn})$ to inactive $(\mathrm{N}+\mathrm{O})$ material increased with carbonization temperature (Fig. S10 $\dagger$ ), which decreased irreversible capacity on the first cycle. Higher CEs observed in tin-TRGO/CNFs carbonized at $850{ }^{\circ} \mathrm{C}$, compared to those carbonized at $650{ }^{\circ} \mathrm{C}$, may also be due to less SEI formation, as specific surface area of carbonized PAN decreases with carbonization temperature. ${ }^{34}$

Rate capabilities of the carbonized electrodes (Fig. 6a and b) were assessed using currents from the calculated capacities presented in Table 1. Discharge capacities from the fifth cycle (example of technique in Fig. S11a $\dagger$ ) were used to represent the capacity at the respective rates. Rate studies on fibers carbonized at $650{ }^{\circ} \mathrm{C}$ revealed high capacities at slower rates, which we attribute to incomplete reduction of non-carbonaceous groups on the formation cycle. For example, TRGO/CNFs with 5 and 10 $\mathrm{wt} \% \mathrm{Sn}(\mathrm{Iv})$ both displayed capacities of $\sim 600 \mathrm{~mA} \mathrm{~h} \mathrm{~g}^{-1}$ at $0.2 \mathrm{C}$ rates. While PAN carbonized at low temperatures led to a disordered carbon structure and tortuous Li-transport pathways, the absence of mass/electron transport limitations at low currents enabled Li to diffuse through the TRGO/CNF structure, into encapsulated Sn particles, and produce large capacities. Capacities decreased as C-rates increased, in part due to ohmic and Li transport limitations. Electrodes comprising $>10 \mathrm{wt} \%$ $\mathrm{Sn}$ (Iv) and carbonized at $650{ }^{\circ} \mathrm{C}$ revealed large irreversible capacities (Fig. S11b $\dagger$ and Table 1) and typically failed after a few cycles. Large irreversible capacity loss was likely due to formation of $\mathrm{Li}_{2} \mathrm{O}$ during irreversible reduction of $\mathrm{SnO}_{2}$ to $\mathrm{Sn}$. Thus, their cycling performance beyond the first cycle was not pursued in this study.

Increasing HTT to $850{ }^{\circ} \mathrm{C}$ produced fibers with larger capacities at fast rates when compared to electrodes produced at $650{ }^{\circ} \mathrm{C}$ (Fig. 6b), which we attribute to a more ordered carbon scaffolding for Sn particles. For example, at 2C rates, electrodes comprising $10 \mathrm{wt} \% \mathrm{Sn}(\mathrm{Iv})$ and heat-treated at $650{ }^{\circ} \mathrm{C}$ produced capacities of $\sim 50 \mathrm{~mA} \mathrm{~h} \mathrm{~g}{ }^{-1}$, whereas electrodes heat-treated at $850{ }^{\circ} \mathrm{C}$ produced capacities of $\sim 500 \mathrm{~mA} \mathrm{~h} \mathrm{~g}^{-1}$. A more ordered

Table 1 List of calculated and experimentally found (actual) first-cycle lithiation capacities and coulombic efficiencies (CEs) in parentheses; calculated capacities were determined using Sn content from EDS. The table also shows the Sn(Iv) content that was added to the fiber precursor

\begin{tabular}{|c|c|c|c|c|c|c|}
\hline $\begin{array}{l}{[\mathrm{Sn}(\mathrm{vI})]} \\
\mathrm{wt} \%\end{array}$ & $\begin{array}{l}{[\mathrm{Sn}]_{650}} \\
(\mathrm{wt} \%)\end{array}$ & $\begin{array}{l}\text { Actual }_{650} \\
{\left[\mathrm{~mA} \mathrm{~h} \mathrm{~g}^{-1}\right](\mathrm{CE} \%)}\end{array}$ & $\begin{array}{l}\text { Calculated }_{650} \\
{\left[\mathrm{~mA} \mathrm{~h} \mathrm{~g}^{-1}\right]}\end{array}$ & $\begin{array}{l}{[\mathrm{Sn}]_{850}} \\
(\mathrm{wt} \%)\end{array}$ & $\begin{array}{l}\text { Actual }_{850} \\
{\left[\mathrm{~mA} \mathrm{~h} \mathrm{~g}^{-1}\right](\mathrm{CE} \%)}\end{array}$ & $\begin{array}{l}\text { Calculated }_{850} \\
{\left[\mathrm{~mA} \mathrm{~h} \mathrm{~g}^{-1}\right]}\end{array}$ \\
\hline 0 & 0 & $1040(75)$ & 375 & 0 & 690 (79) & 375 \\
\hline 10 & 20 & $1320(72)$ & 550 & 21 & $700(80)$ & 508 \\
\hline 15 & 27 & $1200(50)$ & 542 & 23 & $643(78)$ & 523 \\
\hline 30 & 42 & $1260(24)$ & 636 & 41 & $644(76)$ & 632 \\
\hline
\end{tabular}
solution and corresponding Sn content in the carbonized fibers 

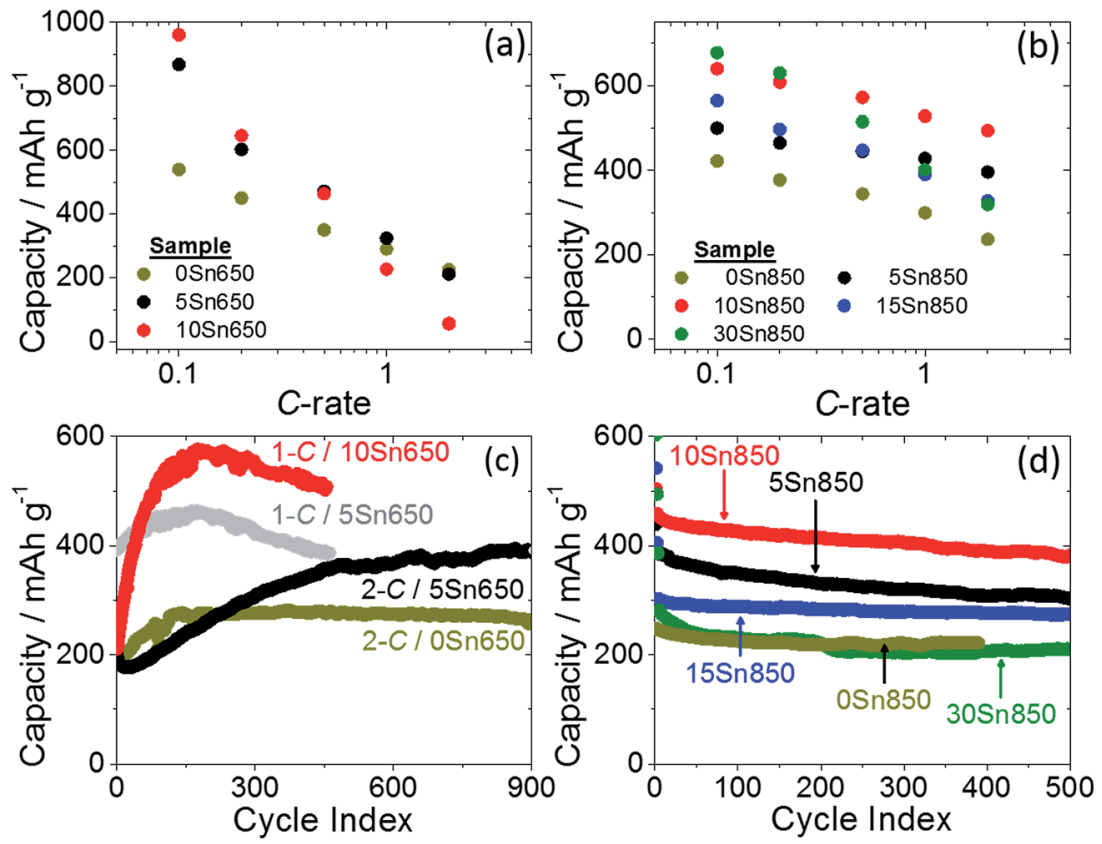

Fig. 6 Rate capability measurements of tin-TRGO/CNFs carbonized at (a) $650{ }^{\circ} \mathrm{C}$ and (b) $850{ }^{\circ} \mathrm{C}$; symmetrical Li-extraction cycling data of tinTRGO/CNFs carbonized at (c) $650{ }^{\circ} \mathrm{C}$ and (d) $850{ }^{\circ} \mathrm{C}$ cycled at $2 \mathrm{C}$ rates.

carbon structure facilitates $\mathrm{Li}$ and electron transport in electrodes. The $I_{\mathrm{D}} / I_{\mathrm{G}}$ ratios (a measure of defects in carbons) calculated from Raman spectroscopy decrease with HTT, which indicates larger graphitic domains and enhanced $\mathrm{sp}^{2}$ ordering (Fig. S12a $\dagger$ ). The enhanced $\mathrm{sp}^{2}$ ordering corresponds to an increased electronic conductivity in the fibers (Fig. S12a †) and decreased internal cell resistances. Increasing HTT also created smaller fibers, which reduced Li diffusion pathway length. Nevertheless, electrodes with Sn(Iv) loadings $>10 \mathrm{wt} \%$ did not produce large capacities at fast rates; large Sn particles on the fiber surface of electrodes carbonized at $850{ }^{\circ} \mathrm{C}$ initially added capacity at cycles with slow C-rates, but cracked/deactivated after successive cycling with faster C-rates (Fig. 6b). We subsequently investigated electrode cycle life over hundreds of cycles to evaluate the robustness of the tin-containing electrodes. Long cycle lives are required for electrodes to be considered for commercial applications.

Extended cycling was executed in half-cells via symmetrical cycling at fast $(\geq 1 \mathrm{C})$ rates. As reported in our previous study, ${ }^{16}$ capacities of TRGO/CNFs carbonized at $650{ }^{\circ} \mathrm{C}$ increase with cycle number, which suggests incomplete reduction of noncarbonaceous species or restructuring of Li-active material. We observed similar results in this study; after capacity increase and stabilization, TRGO/CNF electrodes registered capacities $\sim 270 \mathrm{~mA} \mathrm{~h} \mathrm{~g}^{-1}$, while $5 \mathrm{Sn} 650$ electrodes registered capacities $\sim 400 \mathrm{~mA} \mathrm{~h} \mathrm{~g}^{-1}$ after 900 cycles at $2 \mathrm{C}$ rates-the added capacity is attributed to tin (Fig. 6c). High capacities were also observed at $1 \mathrm{C}$ rates, however capacities faded after 200 cycles. We attribute capacity fade to pulverization and deactivation of Sn within the TRGO/CNF matrix; volume expansions (during lithiation) of encapsulated particles produced strains too great for the fiber matrix to endure.
Contrary to the capacity growth exhibited by fibers carbonized at $650{ }^{\circ} \mathrm{C}$ at $2 \mathrm{C}$ rates, fibers carbonized at $850{ }^{\circ} \mathrm{C}$ exhibited monotonic capacity fade (Fig. 6d). Fibers with Sn(Iv) loadings $>10 \mathrm{wt} \%$ displayed the largest amount of capacity fade; after 500 cycles at $2 \mathrm{C}$ rates, these electrodes revealed capacities similar to TRGO/CNFs in the absence of Sn. The similarity in capacities indicates that the Sn on the surface of the fibers (as seen in Fig. 2e and g) cracked and inactivated. The cracked and inactive Sn particles may be seen in SEM images of 30Sn850 electrodes after 500 cycles in Fig. S13. $\dagger$ Compared to the aforementioned highly loaded Sn electrodes, electrodes with Sn(Iv) loadings $\leq 10$ wt $\%$ exhibited greater capacity retention over 500 cycles at $2 \mathrm{C}$ rates; the $10 \mathrm{Sn} 850$ electrodes displayed capacities $\sim 400 \mathrm{~mA} \mathrm{~h}$ $\mathrm{g}^{-1}$ (>75\% capacity retention), nearly doubling the capacity of TRGO/CNFs in the absence of Sn.

Electrodes comprising $\leq 10 \mathrm{wt} \% \mathrm{Sn}$ (Iv) displayed the largest capacities and capacity retention. We attribute these performance enhancements to the favorable electrode morphology that was produced at low $\mathrm{Sn}(\mathrm{Iv})$ loadings, which resulted in a mechanically durable electrode and limited catastrophic structure rearrangements during lithiation. Favorable electrode morphologies include: (1) encapsulated particles, yet wetted by electrolyte, in the carbon fiber matrix, which were able to impart stresses to the robust scaffolding; (2) small Li-host particle sizes $(\leq 15 \mathrm{~nm}$ ), which resulted in small absolute volume expansions upon Li-insertion; (3) uniform dispersions of tin in the fibers, which limited regions of disproportionate stress and reduced fiber cracking. However, capacity fade exhibited by tincontaining electrodes at capacities greater than $400 \mathrm{~mA} \mathrm{~h} \mathrm{~g}^{-1}$, warrants the necessity for a tailored fiber morphology.

Researchers have proposed that $\mathrm{SnO}_{2}$ electrodes display longer cycle lives and better capacity retention than Sn electrodes. ${ }^{35}$ It is 
thought that the initial reduction of $\mathrm{SnO}_{2}$ (Reaction (1) and (2)) generates lithia-rich regions that hinder $\mathrm{Sn}$ aggregation to retain a small particle size during cycling. However, we did not observe better cycling performances in the $\mathrm{SnO}_{2}$-based electrodes produced at $650{ }^{\circ} \mathrm{C}$, compared to $\mathrm{Sn}$-based electrodes produced at $850^{\circ} \mathrm{C}$. Rather, we attribute differences in cycling performance to the TRGO/CNF scaffolding. After hundreds of cycles at $2 \mathrm{C}$ rates, $\mathrm{SnO}_{2}$-TRGO/CNF electrodes produced at $650{ }^{\circ} \mathrm{C}$ and $\mathrm{Sn}-\mathrm{TRGO} /$ $\mathrm{CNF}$ electrodes produced at $850{ }^{\circ} \mathrm{C}$ exhibited similar capacities. Additionally, electrode microstructure of both $\mathrm{Sn}$ and $\mathrm{SnO}_{2}$ TRGO/CNFs using Sn(Iv) loadings of 5 wt $\%$ appeared similar after 500 cycles. SEM images of 5Sn650 (washed in EMC and dried in the glovebox) after 900 cycles at 2C (Fig. 7a) and 500 cycles at 2C in $5 \mathrm{Sn} 850$ (Fig. $7 \mathrm{~b}$ ) revealed a nonwoven structure similar to precycled electrodes (picture in Fig. S3† and 2).

The promising capacity retention of tin-TRGO/CNF electrodes is attributed, in part, to high CEs; fibers carbonized at $650{ }^{\circ} \mathrm{C}$ displayed average CEs $\geq 99.8 \%$ for $1 \mathrm{C}$ rates and $\geq 99.9$ for $2 \mathrm{C}$ rates (Table $\mathrm{S} 1 \dagger$ ). Average CEs decreased to $\geq 99.2 \%$ for fibers carbonized at $850{ }^{\circ} \mathrm{C}$ (Table $\mathrm{S} 2 \dagger$ ), which may be associated with capacity fade. The presence of TRGO in the CNFs may have increased electrode tensile properties, such as interfacial shear strength, ${ }^{36}$ which enabled TRGO/CNFs with small, encapsulated tin particles to cycle without recurrent cracking/SEI formation. Additionally, we did not observe Sn particle agglomeration upon cycling (other than previously observed upon thermal treatments), suggesting that loadings $<15 \mathrm{wt} \% \mathrm{Sn}(\mathrm{Iv})$ produced particle sizes within TRGO/CNF favorable for LIB anodes. In contrast to the uncycled electrode particles (Fig. 2f), the Sn particles of $15 \mathrm{Sn} 850$ after 500 cycles at 2C rate (Fig. 7c) show a highly roughened surface, indicating significant fracturing. EDS map of the fractured Sn particle reveal SEI formation; concentrated regions of electrolyte salt decomposition products (fluorine and phosphorous maps) and electrolyte solvent reduction and polymerization (oxygen map) appear on the fractured Sn particle. It is likely that formation of the SEI on the Sn particles ohmically limited the electrodes, which decreased capacity at fast rates (as seen in Fig. 6b). As previously mentioned, N-rich regions appear on the EDS maps of pulverized Sn-particle, which is not a decomposition product of the electrolyte. Introduction of nitrogen most likely occurred during electrode processing, and we are currently investigating the electrochemical performance of $\mathrm{Sn}_{x} \mathrm{~N}_{y}$-based electrodes.

\section{Summary}

In this study, we used thermally reduced graphene oxidecontaining carbon nanofibers (TRGO/CNFs) as a matrix for tin particles to produce high-capacity and high-capacity retention anodes for Li-ion battery applications. The Sn-precursor, $\mathrm{SnCl}_{4}$, was electrospun with ethylene glycol, polyacrylonitrile (PAN), and exfoliated graphene oxide, followed by heat treatments to produce $\mathrm{Sn}$ or $\mathrm{SnO}_{2}$-TRGO/CNFs. The effects of heat-treatment temperature and Sn(Iv) loading on fiber structure and morphology were assessed. Oxidation state of $\mathrm{Sn}$ within the fiber mat, inferred from cyclic voltammetry, varied with carbonization temperature; $\mathrm{SnO}_{2}$ and $\mathrm{Sn}(0)$ were produced at 650 and $850{ }^{\circ} \mathrm{C}$, respectively. Thermal decomposition of PAN released $\mathrm{H}_{2}$ at $850{ }^{\circ} \mathrm{C}$, facilitating the high-temperature carbothermal reduction of $\mathrm{Sn}(\mathrm{Iv})$ to $\mathrm{Sn}(0)$. Increased HTT also volatilized Sn-EG entities, which brought $\mathrm{Sn}$ to the TRGO/CNF surface. Low Sn(Iv) loadings, $\leq 10 \mathrm{wt} \%$, produced small tin particles encapsulated within the TRGO/CNF matrix, whereas high $\mathrm{Sn}(\mathrm{Iv})$ produced large tin particulates on the fibers. The ensuing fiber morphology was critical to electrochemical performance.

Fibers with $\leq 10 \mathrm{wt} \% \mathrm{Sn}$ (Iv) produced the smallest size particles (<15 nm diameter), which reduced absolute volume expansions and led to higher capacities over hundreds of cycles than fibers with larger tin loadings. For example, TRGO/CNFs
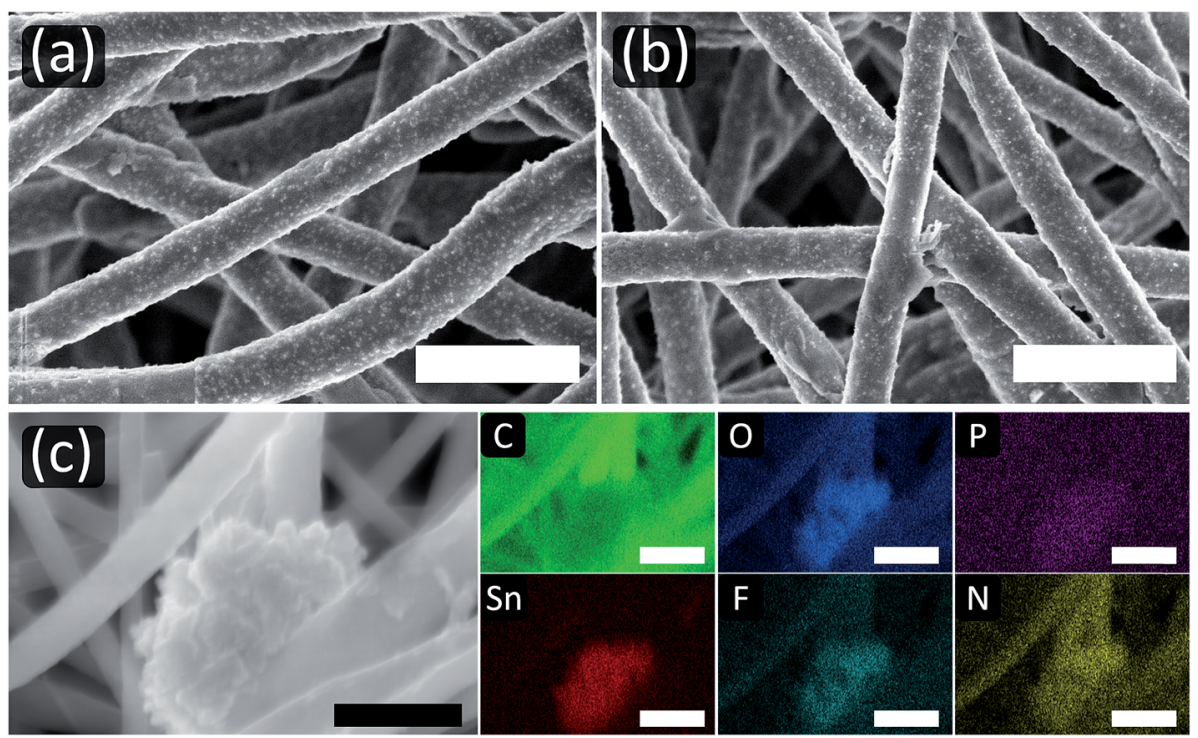

Fig. 7 Post cycle SEM images of (a) 5Sn650 after 900 cycles at 2C, (b) 5 Sn850 after 500 cycles at 2C, and (c) 15 Sn850 after 500 cycles at 2 C with EDS mapping of the individual elements. The scale bars represent $1 \mu \mathrm{m}$. 
with $10 \mathrm{wt} \% \mathrm{Sn}$ (Iv) loading produced capacities $\sim 400 \mathrm{~mA} \mathrm{~h} \mathrm{~g}^{-1}$ after 900 cycles. Fibers with $\leq 10 \mathrm{wt} \% \mathrm{Sn}$ (Iv) also produced fibers with encapsulated particles within the TRGO/CNF matrix that were able to impart their stresses onto the carbon substrate to withstand the mechanical strains of lithiation. The aforementioned particle size and location within the fibers led to a longer cycling life for $\mathrm{Sn}$ and $\mathrm{SnO}_{2}$-TRGO/CNFs. We also attribute the long cycle life at low-Sn(Iv) loadings to uniform dispersion of $\mathrm{Sn}$ (Iv) throughout fiber mats, which created a uniform stress profile across the electrode during lithiation to reduce fiber fragmentation. On the other hand, Sn(Iv) loadings >15 wt $\%$ produced fibers that were not conducive for LIB anodes; large irreversible capacities in $\mathrm{SnO}_{2}$-based fibers and large particles on the TRGO/CNF surface led to large initial capacities, but a short cycle life. Additional research is needed to take full advantage of the large-charge capacity inherent to $\mathrm{Sn} / \mathrm{SnO}_{2}$ anodes. However, this work provides a critical step in producing tin-based anodes that operate at fast rates with high-capacities that endure lithiation over hundreds of cycles.

\section{References}

1 N. Nitta and G. Yushin, High-Capacity Anode Materials for Lithium-Ion Batteries: Choice of Elements and Structures for Active Particles, Part. Part. Syst. Charact., 2014, 31, 317336.

2 H. Li, Z. Wang, L. Chen and X. Huang, Research on Advanced Materials for Li-Ion Batteries, Adv. Mater., 2009, 21, 4593.

3 C.-M. Park, J.-H. Kim, H. Kim and H.-J. Sohn, Li-Alloy Based Anode Materials for Li Secondary Batteries, Chem. Soc. Rev., 2010, 39, 3115-3141.

4 M. Winter and J. O. Besenhard, Electrochemical Lithiation of Tin and Tin-Based Intermetallics and Composites, Electrochim. Acta, 1999, 45, 31-50.

$5 \mathrm{H}$. Inoue, in International meeting on lithium batteries abstract \#228, Biarritz, France, 2006.

6 J. Wolfenstine, J. L. Allen, J. Read and D. Foster, Chemistry and Structure of Sony's Nexelion Li-Ion Electrode Materials, DTIC Document, 2006.

7 Y. Idota, T. Kubota, A. Matsufuji, Y. Maekawa and T. Miyasaka, Tin-Based Amorphous Oxide: A High-Capacity Lithium-Ion-Storage Material, Science, 1997, 276, 1395-1397.

8 V. Etacheri, R. Marom, R. Elazari, G. Salitra and D. Aurbach, Challenges in the Development of Advanced Li-Ion Batteries: A Review, Energy Environ. Sci., 2011, 4, 3243-3262.

9 C. Kim, et al., Fabrication of Electrospinning-Derived Carbon Nanofiber Webs for the Anode Material of Lithium-Ion Secondary Batteries, Adv. Funct. Mater., 2006, 16, 2393-2397.

10 M. Winter, J. O. Besenhard, M. E. Spahr and P. Novak, Insertion Electrode Materials for Rechargeable Lithium Batteries, Adv. Mater., 1998, 10, 725-763.

11 M. Inagaki, Y. Yang and F. Kang, Carbon Nanofibers Prepared Via Electrospinning, Adv. Mater., 2012, 24, 2547-2566.

12 B. Zhang, F. Kang, J.-M. Tarascon and J.-K. Kim, Recent Advances in Electrospun Carbon Nanofibers and Their Application in Electrochemical Energy Storage, Prog. Mater. Sci., 2016, 76, 319-380.
13 Y. Wu, M. Reddy, B. Chowdari and S. Ramakrishna, LongTerm Cycling Studies on Electrospun Carbon Nanofibers as Anode Material for Lithium Ion Batteries, ACS Appl. Mater. Interfaces, 2013, 5, 12175-12184.

14 L. Ji and X. Zhang, Electrospun Carbon Nanofibers Containing Silicon Particles as an Energy-Storage Medium, Carbon, 2009, 47, 3219-3226.

15 C. Bonino, et al., Electrospun Carbon-Tin Oxide Composite Nanofibers for Use as Lithium Ion Battery Anodes, ACS Appl. Mater. Interfaces, 2011, 3, 2534-2542.

16 M. K. Dufficy, S. A. Khan and P. S. Fedkiw, Hierarchical Graphene-Containing Carbon Nanofibers for Lithium-Ion Battery Anodes, ACS Appl. Mater. Interfaces, 2016, 8, 13271336.

17 C. Tang, A. E. Ozcam, B. Stout and S. A. Khan, Effect of Ph on Protein Distribution in Electrospun Pva/Bsa Composite Nanofibers, Biomacromolecules, 2012, 13, 1269-1278.

18 H. Fong, I. Chun and D. Reneker, Beaded Nanofibers Formed During Electrospinning, Polymer, 1999, 40, 4585-4592.

19 J. Wang, W.-L. Song, Z. Wang, L.-Z. Fan and Y. Zhang, Facile Fabrication of Binder-Free Metallic Tin Nanoparticle/Carbon Nanofiber Hybrid Electrodes for Lithium-Ion Batteries, Electrochim. Acta, 2015, 153, 468-475.

20 M. Rahaman, A. F. Ismail and A. Mustafa, A Review of Heat Treatment on Polyacrylonitrile Fiber, Polym. Degrad. Stab., 2007, 92, 1421-1432.

21 B. Saha and G. C. Schatz, Carbonization in Polyacrylonitrile (Pan) Based Carbon Fibers Studied by Reaxff Molecular Dynamics Simulations, J. Phys. Chem. B, 2012, 116, 46844692.

22 S. Yang, H. Song and X. Chen, Nanosized Tin and Tin Oxides Loaded Expanded Mesocarbon Microbeads as Negative Electrode Material for Lithium-Ion Batteries, J. Power Sources, 2007, 173, 487-494.

23 G. Zhang and M. Liu, Preparation of Nanostructured Tin Oxide Using a Sol-Gel Process Based on Tin Tetrachloride and Ethylene Glycol, J. Mater. Sci., 1999, 34, 3213-3219.

24 S. Ye and A. K. Vijh, A New Fuel Cell Electrocatalyst Based on Carbonized Polyacrylonitrile Foam the Nature of PlatinumSupport Interactions, J. Electrochem. Soc., 1997, 144, 90-95.

25 L. G. Bulusheva, et al., Electrochemical Properties of Nitrogen-Doped Carbon Nanotube Anode in Li-Ion Batteries, Carbon, 2011, 49, 4013-4023.

26 S. V. Nand, K. Ankur, K. Brijesh and M. B. Raj, Synthesis of Single Phase Cubic Tin Nitride Nanoparticles by Atmospheric Pressure-Halide Vapor Phase Epitaxy, Solid State Sci., 2008, 10, 569-572.

27 A. Othonos and M. Zervos, Carrier Relaxation Dynamics in Snxny Nanowires Grown by Chemical Vapor Deposition, $J$. Appl. Phys., 2009, 106, 114303.

28 X. Zhou, L. J. Wan and Y. G. Guo, Binding $\mathrm{SnO}_{2}$ Nanocrystals in Nitrogen-Doped Graphene Sheets as Anode Materials for Lithium-Ion Batteries, Adv. Mater., 2013, 25, 2152-2157.

29 Z. Zhu, et al., Ultrasmall Sn Nanoparticles Embedded in Nitrogen-Doped Porous Carbon as High-Performance Anode for Lithium-Ion Batteries, Nano Lett., 2013, 14, 153157. 
30 Y.-J. Kim, H. Lee and H.-J. Sohn, Lithia Formation Mechanism in Tin Oxide Anodes for Lithium-Ion Rechargeable Batteries, Electrochem. Commun., 2009, 11, 2125-2128.

31 I. Courtney, J. Tse, O. Mao, J. Hafner and J. Dahn, Ab Initio Calculation of the Lithium-Tin Voltage Profile, Phys. Rev. B: Condens. Matter Mater. Phys., 1998, 58, 15583.

32 Z. Chen, et al., In Situ Generation of Few-Layer Graphene Coatings on $\mathrm{SnO}_{2}$-Sic Core-Shell Nanoparticles for HighPerformance Lithium-Ion Storage, Adv. Energy Mater., 2012, 2, 95-102.

33 Y. Chen, B. Song, R. M. Chen, L. Lu and J. Xue, A Study of the Superior Electrochemical Performance of $3 \mathrm{Nm} \mathrm{SnO}_{2}$
Nanoparticles Supported by Graphene, J. Mater. Chem. A, 2014, 2, 5688-5695.

34 D.-K. Kim, et al., Electrospun Polyacrylonitrile-Based Carbon Nanofibers and Their Hydrogen Storages, Macromol. Res., 2005, 13, 521-528.

35 I. A. Courtney and J. Dahn, Electrochemical and in Situ X-Ray Diffraction Studies of the Reaction of Lithium with Tin Oxide Composites, J. Electrochem. Soc., 1997, 144, 20452052.

36 X. Zhang, X. Fan, C. Yan, H. Li, Y. Zhu, X. Li and L. Yu, Interfacial microstructure and properties of carbon fiber composites modified with graphene oxide, ACS Appl. Mater. Interfaces, 2012, 4, 1543-1552. 